Araştırma Makalesi / Research Article

\title{
BATI KÜLTÜRÜNÜN OSMANLI TOPLUMUNA TAŞINMASINDA ÖNEMLİ BİR UNSUR OLARAK KADIN DERGILERI
}

\author{
Neslihan KILIÇ* \\ WOMEN'S MAGAZINES AS AN IMPORTANT ELEMENT \\ IN THE MOVEMENT OF WEST CULTURE TO OTTOMAN \\ SOCIETY
}

$\ddot{O} \mathbf{z}$

Tarihsel olarak kültür değişimi genellikle bir kültürün bir başka kültürle teması sonucu ortaya çıkmıştır. Bu süreçte rol oynayan en temel kurumlardan biri basındır. Bu yönüyle basın, Batı kültürünün Osmanlı toplumuna taşınmasında önemli bir rol oynamıştır. Dönemin kadın dergilerinde hâkim olan düşünce, toplumun modernleşmesinin, kadının dönüşümüyle mümkün olacağ 1 şeklindedir. Kadın dergilerinde ele alınan kadının eğitimi, kadın-erkek eşitliği, kadının toplumsal statüsü, moda, kadının giyim kuşamı, saç ve güzellik gibi konularla Osmanlı kadın kimliği Batılılaşma/modernleşme yolunda önemli mesafeler kat etmiştir. Çalışmanın dönemsel kapsamı 1860-1923 yılları arasındaki kadın dergileridir. Çalışmanın sınırlılığ 1 ise dergilerde ele alınan çok çeşitli konular arasından kadının görünürlüğüne ilişkin kılık kıyafet ve buna yönelik reklamlardır. Çalışmanın amacı, Batı kültürünün Osmanlı toplumuna taşınmasında dönemin kadın dergilerinin rolünü irdelemektir. Giyim kuşam, saç ve güzellik gibi görünür öğelere sayfalarında bolca yer veren Osmanlı kadın dergilerinin Batı kültürünün Osmanlı toplumuna taşınmasında önemli bir rolü olduğuna çalışmanın sonucunda ulaşılmıştır.

Anahtar Kelimeler: Osmanlı Modernleşmesi, Batılılaşma, Osmanlı Kadın Dergileri.

\begin{abstract}
Historically, cultural change has generally occurred as a result of a culture's contact with another culture. One of the main institutions that play a role in this process is the press. In this respect, the press played an important role in the transfer of western culture to Ottoman society. The idea that prevailed in women's magazines of the period is that the modernization of society will be possible by the transformation of women. Ottoman women's identity has made great strides towards westernization / modernization with issues such as
\end{abstract}

\footnotetext{
* Dr. Öğr. Üyesi, Dicle Üniversitesi, İletişim Fakültesi, Genel Gazetecilik ABD, e-posta: nsevenkilic@gmail.com, https://orcid.org/0000-0001-6742-6442.

Makale Gönderim Tarihi: 12.06.2020 https://doi.org/10.11616/basbed.v20i56819.756039 Makale Kabul Tarihi $\quad: 17.09 .2020$
} 
women's education, gender equality, women's social status, fashion, women's clothing, hair and beauty, which have been discussed in women's magazines. The periodic scope of the study is women's magazines between 1860-1923. The limitation of the study is disguise dress and advertisements aimed at the visibility of women among the wide variety of topics covered in magazines. The aim of the study is to examine the role of women's magazines of the period in the transfer of Western culture to Ottoman society. As a result of the study, it was found that Ottoman women's magazines, which include visible elements such as clothing, hair and beauty, played an important role in the transfer of Western culture to Ottoman society.

Keywords: Ottoman Modernization, Westernization, Ottoman Women's Magazines.

\section{Giriş}

1839 tarihli Tanzimat Fermanı bir padişah buyruğu olmanın ötesinde çok farklı anlamlara sahiptir. Osmanlı Devleti için dönüm noktalarından biri olarak kabul edilen Tanzimat Fermanı ile devletin ve toplumun bütün kurumlarında köklü değişiklikler meydana gelmiş, bu değişimin etkileri Cumhuriyetin kuruluş döneminden sonra da günümüze kadar süregelmiştir. Osmanlı Devleti'nde Batılılaşma (modernleşme/alafrangalılık) esasen Tanzimat'tan çok önceki tarihlere gitmekle birlikte Tanzimat ile birlikte Batılilaşma, toplumun tüm katmanlarını etkileyecek şekilde meydana gelmiştir (Lewis, 1984:214).

Tanzimat Fermanı'nda ilan edilen kimi hususların gerçekleştirilmesinde yaşanan problemlerin giderilmesi amaciyla ilan edilen 1856 tarihli Islahat Fermanı ve 1908'de ilan edilen II. Meşrutiyet, Batılılaşma hareketinin diğer önemli dönüm noktalarıdır. Beraberinde oldukça radikal sosyal ve siyasal sonuçlar doğuran Batılılaşma hareketi, Osmanlı'da basının da gelişimine zemin hazırlamıştır (Nalcıoğlu, 2005:253).

Osmanlı Devleti'nde Batılılaşma hareketi basın faaliyetleriyle oldukça yakın ilişki içinde olmuştur. Çünkü Batılılaşma ve basın birbirlerinin zorunlu sonucu olarak ortaya çıkmış ve her ikisinin gelişimi birbirlerinden beslenmiştir. 1830'lu yıllarda ilk örnekleri ortaya çıkan gazeteler zamanla belirli bir toplumsal zemine kavuşmuş, bu durum kadın gazete ve dergilerinin doğuşuna da öncülük etmiştir.

Kadın gazete ve dergilerinin Osmanlı modernleşmesinde çok önemli bir işlevi olmuştur. Bu dönem yayınlanan bütün kadın gazete ve dergilerinde hâkim olan düşünce, toplumun modernleşmesinin, kadının dönüşümüyle mümkün olacağı şeklindedir. Ancak muhafazakâr çizgide yayın yapan kadın gazete ve dergileri bu dönüşümü milli ve manevi değerler istikametinde ele alırken, Batı yanlısı çizgide yayın yapanlar ise bu 
dönüşümü "Batılılaşma" istikametinde ele almışlardır. Bununla birlikte genelde basın, özelde ise kadın dergileri Osmanlı toplumunun kültürel yapısının değişiminde önemli etkiler meydana getirmiştir. $\mathrm{Bu}$ açıdan bakıldığında kültür, en genel anlamıyla bir toplumun yaşam tarzı olarak ifade edilen ve bilgi, inanç, gelenek görenek, örf ve adet, ahlak, sanat, teknik vb. gibi maddi ve manevi unsurlardan oluşan karmaşık bir bütündür. Bina, araç-gereç, giyim tarzı vb. unsurlar kültürün maddi öğelerini oluştururken, din, inanç, gelenek görenek, örf ve adet, ahlak, sanat ve düşünce tarzı kültürün manevi öğelerini oluşturmaktadır (Gökalp, 2013:100). Bir toplumun maddi ve manevi kültür ögelerinin bir şekilden başka bir şekle geçmesi, yapı ve önemlerinin başkalaşması ise kültür değişmesi olarak ifade edilmektedir. $\mathrm{Bu}$ değişimler daha ziyade başka kültürlerle temas sonucunda ortaya çıkmaktadır (Gökalp, 2013:103). İşte bu çalışmada Batı kültürünün Osmanlı toplumuna taşınmasında diğer bir ifadeyle Osmanlı toplumunun kültür algısının değişiminde kadın gazete ve dergilerinin etkileri somut örnekler üzerinden ele alınmıștır. Bu dönemde gazete ve dergi kavramı birbirinden kesin çizgilerle ayrılmadığı için kimi kaynaklar bu yayınlardan "gazete", kimileriyse "dergi" olarak söz etmektedir. Makalede genel bir ifade olarak "kadın dergileri" kullanılacaktır.

Çalışmanın temel varsayımı, Batı kültürünün Osmanlı toplumuna taşınmasında Cumhuriyet öncesi 1860-1923'lü yıllar arasında yayımlanan Osmanlı kadın dergilerinin önemli bir rolü olduğudur. Makale, 18601923'lü yıllar arasında yayımlanan Osmanlı kadın dergilerinde kadın giyimi ve moda ile ilgili konularla sınırlandırılmış olup yine bu dönem yayınlanan kadın dergilerinde rastlanan kadın-erkek eşitliği, kadının sosyal hayattaki konumu, kadının eğitimi ve kadının çalışma hakkı gibi Batılılaşmanın diğer tezahürü konular ise kapsam dişı bırakılmıştır.

\section{Genel Hatlarıyla Osmanlı Modernleşmesi}

Osmanlı İmparatorluğu, 18. yy.dan sonra bir çöküş sürecine girmiştir. Bu çöküşte etkili olan iki temel sebepten biri savaşlarda alınan ağır yenilgiler diğeri ise Avrupa devletlerinin Reform, Rönesans ve Sanayi Devrimiyle hızla modernleşmesi ve güçlenmesidir. İmparatorluk, bu durumun düzeltilmesi için çeşitli arayışlara girmiş ve Batılı devletlerin örnek alındığ1 çeşitli ıslahat faaliyetlerinde bulunmuştur (Budak, 2014:12). Böylece Osmanlı Devleti'nin Batılılaşma/modernleşme süreci başlamıştır.

Savaşlarda alınan ağır yenilgilerinden dolayı yapılan ilk 1slahat faaliyetlerinin merkezinde ordunun modernleştirilmesi bulunmaktadır (Lewis, 1984:75). Özellikle III. Selim ve II. Mahmut dönemlerinde 
başlayan modernleşme çabaları, Batı'yla giderek artan ilişkilerin de etkisiyle zamanla başka alanlara da yayılmıștır (Berkes, 2012:41). Osmanlı modernleşmesinin dönüm noktası 1839 yılında ilan edilen Tanzimat Fermanı'dır. Tanzimat Dönemi (1839-1871) devletin adeta kabuk değiştirdiği bir dönemdir. Özellikle idari alanda merkezileşme çabaları, eğitimin geniş kitlelere devlet eliyle sunulması, modern okulların kurulmasına hız verilmesi ve kanunlaştırma hareketleri, reformların en önemli unsurları olmuştur (Berkes, 2012:214).

Yapılan çeşitli düzenlemelerin etkileri sadece ilgili alanla sınırlı kalmamış başta aile hayatı olmak üzere toplumsal hayatın pek çok kurumunda görülmüştür. $\mathrm{Bu}$ değişim beraberinde kadının merkeze alındığı tartışmaların da önünü açmıştır. Kadının eğitimi, aile hayatındaki yeri, sosyal hayata katılımı, giyimi ve toplumdaki statüsü tartış1lan belli başlı konular arasındadır (Ortaylı, 1984:78). 1847 yılında köleliğin ve cariyeliğin kaldırılması, 1858 tarihli Arazi Kanunu'yla kadınların da mirasa ortak kılınması, 1881 Sicil-i Nüfus Nizamnâmesi ile evliliğe resmi bir boyut kazandırılması kadınların önemli derecede lehlerine olan düzenlemelerdir (Çaha, 1996:88).

Dönemin, kadını doğrudan ilgilendiren esas düzenlemeleri ise eğitim alanında yaşanmıştır. II. Mahmut döneminden itibaren modern kız okullarının açılması, 1842'de Avrupa'dan getirilen ebelerin Osmanlı kadınlarına verdikleri eğitimle kadının meslek sahibi olmaya başlaması, 1868 Meârif-i Umûmiye Nizamnâmesiyle 6-11 yaşları arasındaki tüm kız çocuklarının ilkokul eğitimi almalarının öngörülmesi ve 1876 tarihli Kanun-i Esasi' de ise kadın erkek tüm Osmanlı nüfusunun ilkokul eğitimi almasının zorunlu kılınması eğitim alanında kadınlara yönelik yapılan önemli düzenlemelerdir (Çaha, 1996:89). Kız çocuklarının genel eğitim içinde yer almaları, bu eğitimleri verecek kadın öğretmen ihtiyacını doğurmuş ve 1870 y1lında Dârü'l-Muallimât (Kız Öğretmen Okulu) açılmıştır (Tekeli, 1985:1190-1204).

Eğitim alanında yapılan belli başlı bu düzenlemelerle birlikte ülkede kadın okur-yazar sayısı hızla artmaya başlamış, ilk adımları Tanzimat Dönemi'nde atılan bu faaliyetler meyvesini Meşrutiyet Dönemi'nde vermiştir. $\mathrm{Bu}$ dönemden itibaren kadın, gazete ve dergilerle basın hayatında, birtakım derneklerle de sosyal hayatta söz sahibi olmaya başlamıştır (Kurnaz, 1990:62).

\section{Osmanlı Kadın Dergileri}

Kadın dergileri, Osmanlı modernleşme hareketlerinin en somut göstergelerinden ve sonuçlarından biridir (Çakır, 1996:23). Tanzimat 
Dönemi'nde ilk örneklerini gördüğümüz kadın dergilerinin sayıs1 Meşrutiyet sonrası basın hayatında oluşan özgürlük havasından etkilenerek artmıştır (Yıldırım ve Seyhan, 2015:46). Dönemin kadın dergileri, yazar ve sahiplerinin kadın veya erkeklerden oluşmasına bağlı olarak da farkl1liklar göstermektedir. Şükûfezâr, Seyyâle, Kadınlar Dünyası, Siyânet, Diyâne gibi dergiler sahiplerinin ve yazarlarının kadın olması sebebiyle doğrudan kadınların duygu ve düşüncelerini aktarırken, erkek yazarların baskın olduğu dergilerde, kadınlar erkek bakış açısıyla değerlendirilerek ideal kadın profili ortaya konulmaya çalışılmıştır (Özen, 1994:17).

Sadece kadın dergileri değil dönemin bütün yayınları için tiraj konusunda net bir bilgi bulunmamaktadır. Ancak kadın dergilerinde çeşitli vesilelerle yer alan yazılardan tiraj konusunda yaklaşık bir tahmin yürütmek mümkündür. Örneğin; İnci dergisinde düzenlenen bir bilgi yarışmasına beş yüzden fazla cevap gelmesi ve dereceye girenlerin belirlenmesinde güçlükle karşılaşılmasından dolayı sonucun, doğru cevap verenler arasından kurayla belirleneceğine dair dergide yayınlanan bir bilgi notundan, derginin binlerle ifade edilecek bir tiraja sahip olduğu sonucunu çıkartmak mümkündür (İnci, 1 Nisan 1919:12)

İlk örnekleri genellikle bir gazetenin eki olarak çıkan Osmanlı kadın dergileri zaman içinde müstakil olarak da yayımlanmaya başlamıştır. Dergilerin içerikleri ana hatlarıyla; ev işleri, çocuk sağlığı ve terbiyesi, pasta ve yemek tarifleri, moda, dikiş, nakış, evlilik, eşlerin davranışları ve sorumlulukları, tek eşlilik, kadın-erkek eşitliği, kadının eğitimi, kadınlara çalışma hakkının tanınması, çeşitli cemiyet haberleri, İslam ve Batı kadınlarının yaşam tarzları, resim, tiyatro, edebiyat gibi alanlarda ismini duyurmuş kadınların hayatları ve eserleri gibi konulardan oluşmaktadır (Kılıç, 2019:24).

Yukarıda da belirttiğimiz gibi bu dönemde çok sayıda kadın dergisi yayımlanmıştır. Kaynaklardan ulaşılan dönem içinde yayımlanan kadın dergileri Tablo 1'de listelenmiştir: 
Tablo 1: 1860-1923 Yilları Arasında Yayımlanan Kadın Dergileri

\begin{tabular}{|c|c|c|c|c|}
\hline Dergi Adı & $\begin{array}{l}\text { Yayın } \\
\text { Tarihi }\end{array}$ & Periyodu & İmtiyaz Sahibi & $\begin{array}{l}\text { Yayın } \\
\text { Yeri }\end{array}$ \\
\hline Terakkî-i Muhadderât & 27.06 .1869 & Haftalık & Ali Raşit & İstanbul \\
\hline $\begin{array}{l}\text { Vakit Yahut Mürebbi-i } \\
\text { Muhadderât }\end{array}$ & 26.09 .1875 & Haftalık & Filip Efendi & İstanbul \\
\hline Ayine & 14.11 .1876 & Haftalık & Mustafa Bey, Hamdi Bey & Selanik \\
\hline Aile & 27.05 .1880 & Haftalık & Mihran & İstanbul \\
\hline İnsaniyet & $1882-1883$ & Aylık & Mahmut Celalettin & İstanbul \\
\hline Hanımlar & Kasım 1882 & Aylik & Cafer & İstanbul \\
\hline Şüküfezar & 1886 & 15 Günlük & Ârife Hanım & İstanbul \\
\hline Mürüvvet & 28.02 .1888 & Haftalık & Mahmut Celalettin & İstanbul \\
\hline Parça Bohçası & 1889 & 15 Günlük & Hatice Semiha & İstanbul \\
\hline $\begin{array}{l}\text { Hanımlara Mahsus } \\
\text { Gazete }\end{array}$ & 31.08 .1895 & Haftalık & $\begin{array}{l}\text { İbn-ül-Hakkı Mehmet } \\
\text { Tâhir }\end{array}$ & İstanbul \\
\hline Alem-i Nisvan & 3.03 .1906 & Haftalık & İsmail Gaspıralı & Kırım \\
\hline Mehâsin & 14.09 .1908 & Aylık & Mehmet Rauf & İstanbul \\
\hline Demet & 30.09 .1908 & Haftalık & Hakk1 Bey & İstanbul \\
\hline Kadın & 26.10 .1908 & Haftalık & Muhammed İbrahim & Selanik \\
\hline Musavver Kadın & 16.04 .1911 & 15 günlük & $\begin{array}{l}\text { Süleyman Bahri, } \\
\text { Nizameddin Hasib }\end{array}$ & İstanbul \\
\hline Kadın & 24.08 .1911 & Haftalık & Nizamettin Hasib & İstanbul \\
\hline Kadınlar Dünyası & 17.04 .1913 & Günlük & Nuriye Ulviye & İstanbul \\
\hline Kadınlık Hayatı & 1913 & & Emine Seher Ali & İstanbul \\
\hline Erkekler Dünyası & 19.01 .1914 & Tek sayı & Rifat & İstanbul \\
\hline Kadınlık & 21.03 .1914 & Haftalık & Hacı Cemal & İstanbul \\
\hline Hanımlar Alemi & 9.04 .1914 & Haftalık & Mehmet Asaf & İstanbul \\
\hline Kadınlar Alemi & 4.06 .1914 & Haftalık & Naci & İstanbul \\
\hline Seyyale & 4.06 .1914 & Tek sayı & Adile Necati & İstanbul \\
\hline Siyanet & 4.06 .1914 & Haftalık & Melek Meliha & İstanbul \\
\hline Bilgi Yurdu Işı̆̆ 1 & 15.04 .1917 & Aylık & Ahmet Edip & İstanbul \\
\hline Türk Kadını & 23.05 .1918 & 15 günlük & Muallim Ahmet Halit & İstanbul \\
\hline \begin{tabular}{|l|} 
Genç Kadın \\
(Seyit Tahir)
\end{tabular} & 24.10 .1918 & 15 günlük & Seyit Tahir & İstanbul \\
\hline Genç Kadın & 4.01 .1919 & 15 günlük & $\begin{array}{l}\text { Karahisarlı Muaalim } \\
\text { Fuat Şükrü }\end{array}$ & İstanbul \\
\hline Inci & 1.02 .1919 & Aylik & Sedat Simavi & İstanbul \\
\hline Diyane & 12.03 .1920 & 15 günlük & Seza Pehu & İstanbul \\
\hline Kadınlar Saltanatı & 5.04 .1920 & Tek sayı & Sedat Simavi & İstanbul \\
\hline Hanım & 1.09 .1921 & Aylik & Sedat Simavi & İstanbul \\
\hline Yeni İnci & \begin{tabular}{|l} 
Haziran \\
1922
\end{tabular} & Aylık & Sedat Simavi & İstanbul \\
\hline Süs & 16.06 .1923 & Haftalık & Mehmet Rauf & İstanbul \\
\hline Ev Hocas1 & 1.07 .1923 & Tek sayı & Ahmet Edip & İstanbul \\
\hline
\end{tabular}




\section{Kadın Dergilerinin Osmanlı Modernleşmesindeki Rolü}

Osmanlı dönemi kadın dergileri kadının eğitimi, kadın-erkek eşitliği, kadının toplumsal statüsü, moda, kadının giyim kuşamı, saç ve güzellik gibi ele aldığı konularla Osmanlı kadın kimliğinin Batılılaşmasında/modernleşmesinde önemli bir etkiye sahip olmuştur. Çalışmada, bu etkinin izleri kadının görünürlüğüne ilişkin kılık kıyafet ve buna yönelik reklamlar üzerinden incelenmiştir. Bilindiği üzere Batıcılık dönemin önde gelen düşünce akımlarındandır. Çalışmaya esas olan örnekler de dönemin Batıcılık yanlısı yayın politikası izleyen Hanım, Hanımlara Mahsus Gazete, Inci, Kadınlar Dünyası, Mehâsin dergilerinden seçilmiştir.

\subsection{Kültür Taşınmasını Kılık-Kıyafet Üzerinden Okumak}

Dönemin kadın dergilerinde ele alınan en önemli konulardan biri giyim ve saç modelleri üzerinden kadının dış görünüşüne dair tartışmalardır. $\mathrm{Bu}$ tartışmaların toplumda meydana geldiğini, bunun da gazete ve dergilere yansıdığını göstermesi açısından bu dönemde kurulan kadın derneklerinden birinin isminin "Sade Giyinen Hanımlar Derneği" olması dikkate değerdir (Sürücü, 2008:54). Diğer bir ifadeyle bu derneğin varlığı, kadın giyiminin gazete ve dergilerde tartışılan suni bir konu olmadığını, toplumda karşılığı olan bir konunun basına da yansıdığını bizlere göstermektedir.

Kadın giyimiyle ilgili tartışmalar başlangıçta tesettür üzerinden ele alınmış, çarşaf ve peçe etrafında dönen tartışmalarda farklı düşünceler seslendirilmiştir. $\mathrm{Bu}$ çerçevede gündeme gelen ve bütün kadın dergilerinde sıklıkla kullanılan bir kavram da moda'dır. 1840'l1 yıllardan itibaren hız kazanan modernleşme hareketlerinin, kadının dış görünümünü etkilediğini, bunun da doğrudan kadın giyimine tesir ettiğini göstermesi açısından dönemin önde gelen kadın dergilerinden İnci'de yer alan şu satırlar dikkat çekicidir:

"Moda Türk hanımının hayatında mühim bir âmil olmaya başladı. Yeni hayatın telakkilerimizde îka ettiği tebeddüller kıyafetlerimize tesirden hâlî kalmıyor. Bugün Türk kadınını sokakta, çarşıda, mektepte, resmi dairelerde hatta uzun seyahatlerde görüyoruz. İslam hanımı haremde yani umumi hayatın dairesi hâricinde tamamıla mu'tekif bir ömür geçirirken nadir tesadüfle sokă̆a çıktı̆̆l vakit gözünün içine kadar her tarafinı sıkı sıkı örtebilirdi. Hâlbuki hayat şerâiti artık büsbütün değişmiştir. Çarşı işlerini görmek, îfâsına memur olunan vazifeleri yapmak, muallimleri dinlemek, vapura tramvaya binmek ve büyük şehirlerin kalabalık, muhtelif nakliye vasitalarıla mütalâtim binaenaleyh tehlikeli sokaklarda dolaşmak için kulağın tıkalı olmaması, gözün kalın 
bir perde altında kalmaması, ăgzın söz söyleyebilmesi, bir kelime ile vücudun serbest bulunması iktizâ eder. Bu tesettürün aleyhinde bulunmak değildir" (İnci, 1 Şubat 1919:4).

Dergide Osmanlı-İslam kadınının günlük hayatta riayet ettiği tesettürün aleyhinde olunmadığı ancak bugünkü haliyle kıyafetlerin de Osmanlı kadınına yakışmadığı, nitekim mevcut giyim tarzının İslam dininde karşılığının olmadığı da iddia edilmiştir:

"İslam diniyle alakası olmadığl, bilakis bize Rumlardan, Iranlılardan geçtiği ilmin kati şehadetiyle sâbit olan tesettür ananesinin ırkımızda yaşadığ müddetçe -yalnız bir âdet olarak- devam etmesine şiddetle taraftarı. Din ve ahlak ile hiçbir münasebeti olmayan bu âdetin yalnız bir âdet olmak haysiyetiyle klymeti vardır. Hâlbuki âdetler ırkın tebeddülüyle değişir. Bu da zamanla olur. Binaenaleyh bugünkü telebbüsümüzü tesettür dairesinde islah etmemiz icap eder. Ben yalnız kıyafetlerimizin değişmesinde bizim idare ve ihtiyacımızın değil fakat hayatın yeni istikametlerde inkişâf etmekte olmasının da dahli bulunduğunu söylemek istiyorum" (İnci, 1 Şubat 1919:4).

Yazının devamında Tanzimat'tan beri yapılan çalışmalar dile getirilerek toplumun "asrîleştiği", bu durumun sosyal hayata yansımaları çerçevesinde erkeklerin baştan aşağıya Avrupa tarzı bir görünüm kazandığı ifade edilmekte, erkek giyimi açısından tartışılmayan meselenin kadın giyimi söz konusu olduğunda niçin tartışıldığ 1 sorgulanmaktadır. Ayrıca kadın giyiminin tıpkı erkek giyiminde olduğu gibi Batı'dan aynen taklit edilmesinin yanlış olacağı, milli telakkilere uygun bir modanın oluşturulması gerektiği şu şekilde ifade edilmektedir:

"Fakat kıyafetimizin değişmesini zaruri görmekle beraber Türk kadınının doğrudan doğruya garp modasına teveccüh etmesini tabii addetmiyorum. Ve kendi kendime soruyorum. Acaba biz Almanların Fransiz modasinı yaptıkları gibi bütün garp modasına karşı milli bir Türk modası hareketi çıkartamaz mıyı?? Erkeklerimizin kavuklarından pabuçlarına kadar bütün giydiklerini ecnebilerinkilerle değiştirirlerken aldıkları şeylere terk ettiklerinden bir şeyler katmak yani eski telebbüsün milli hususiyetini yenilerde ibkâ etmek kaygısına düşmediler. Fakat biz Türk kadınları aynı yolu takip etmemeliyiz. Ve ĕger iyi düşünür mütefekkirlerimizin, muharrirlerimizin, müverrihlerimizin, ressamlarımızın muâvenetlerini de temin edebilirsek zannediyorum ki milli bir moda vücuda getirmekte herhalde Almanlardan daha ziyade muvaffak oluruz. Çünkü Almanlar medeniyet ve hars itibariyle Fransızlarla ve diğer garp milletleriyle pek ziyade karışmış oldukları halde biz öyle değiliz. Pek eski medeniyetlerin tecelligâhı olan şark, bilhassa Türk harsı bize nispeten orijinal bir moda 
ilham edecek zenginliklerle doludur. Bu zenginlikleri keşfeder, onlardan istifade yollarını bulursak garp modasinı maymun gibi fikirsiz taklit etmekten kurtuluruz" (İnci, 1 Şubat 1919:4).

Burada şu hususun altını önemle çizmek gerekmektedir; Tanzimat'ın genel karakteristik özelliklerinden biri olan düalist ${ }^{1}$ yapı kadın dergilerinde de karşımıza çıkmaktadır. Bir yandan yukarıdaki örnekte olduğu üzere "Milli Moda" hakkında yazılar kaleme alınmakta ancak diğer taraftan da aynı dergilerde bu yazının ruhuna aykırı Avrupai tarzda kadın fotoğraf ve illüstrasyonlarına yer verilerek yazı içeriğiyle hiç de uyumlu olmayan bir rol model betimlemesi yapilmaktadır.

Kadın giyiminin toplumsal bir mesele haline gelmesiyle konu Osmanl Kadınları Müdafâa-i Hukuk Cemiyeti'nin programında da yer almıştır. Cemiyet'in bir nevi yayın organı olarak çıkarılan, kesintilerle de olsa 1913'ten 1921 yılına kadar en uzun soluklu kadın dergisi olan ve Osmanlı'da feminist hareketin öncüsü kabul edilen Kadınlar Dünyası'nda "Klyafetimizin Islâhı" başlıklı bir yazı yayınlanmıştır. Yazıda Osmanlı Kadınları Müdafâa-i Hukuk Cemiyeti'nin programında da yer aldığ 1 üzere kadınların kıyafetlerinin yeniden belirlenmesi gerektiği ifade edilmektedir. Buna göre erkeklerin de dâhil olacağı ve gerek İstanbul'dan gerekse taşradan toplumun her kesiminden kadının katılacağı bir seçim yapılmalı ve milli esaslara uygun kıyafet şekillerine karar kılınmalıdır (Kadınlar Dünyası, 30 Mayıs 1329:1). Derginin bütünü üzerinde yapmış olduğumuz incelemede, bu yönde bir seçimin yapıldığına veya yapıldıysa nasıl sonuçlandığına dair bir bilgiye rastlamadık. Ancak yazıda her ne kadar milli esaslara uygun bir klyafet belirlenmesinin gereğinden bahsedilse de derginin ilerleyen sayılarında kıyafet konusunda Osmanlı kadınına rol model olarak sunulan kadın kıyafeti, dönemin Avrupa kadınlarının giyim tarzıdır (Kadınlar Dünyası, 10 Ağustos 1329:9).

1 Tanzimat Dönemi'nde 1slahatlar yapılırken var olan gelenek zemininden hareket edilmiştir. Bir taraftan Batı örnek alınırken, diğer taraftan eski geleneklerden tamamen kopuş yaşanmamıştır. Bunun sonucunda birçok alanda düalist diğer bir ifadeyle ikili bir yapı ortaya çıkmıştır. Ayrıntılı bilgi için bknz. İlber Ortaylı, Osmanlı Düşünce Dünyası ve Tarih Yazımı. Türkiye İş Bankası Kültür Yayınları. 
Resim 1: Kadınlar Dünyası'nda Yer Alan Kadın Kıyafetine Dair Bir Fotoğraf

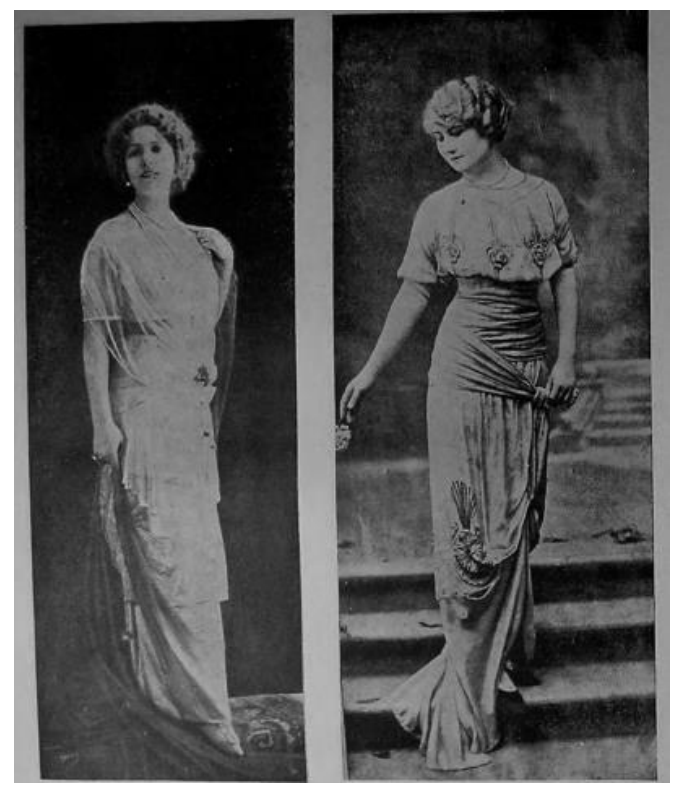

Ayrıca derginin çeşitli sayılarında "Şarkta Kadın" başlıklı yer alan köşede verilen fotoğraf ve illüstrasyon çizimlerde şarkta kadın, hep tipik Anadolu köylü kadını şeklinde verilmiştir (Kadınlar Dünyası, 27 Temmuz 1329:12).

Resim 2: Kadınlar Dünyası'nda "Şarkta Kadın" Başlı̆̆ıyla Yer Alan Bir Fotoğraf

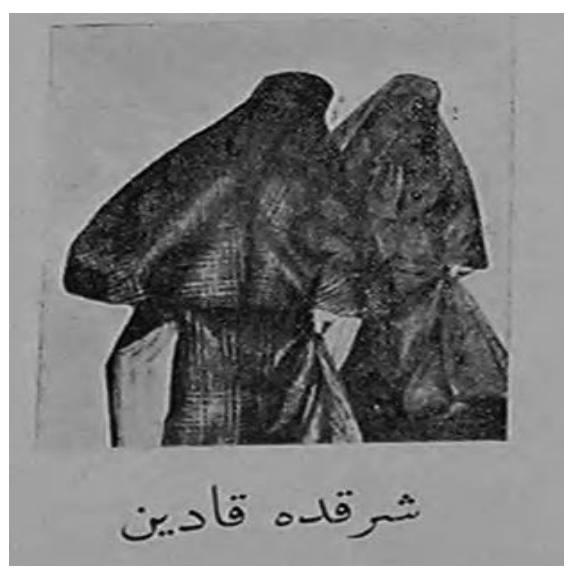

Gerek Osmanlı'da gerekse erken Cumhuriyet döneminde kadın konusunun çoğunlukla dış görünüş üzerinden tartışılmasından dolayı 716 
moda, "medeni" ve "asrî" olmanın meşrulaştırıcı bir unsuru olarak kabul edilmiştir. Dolayısıyla "moda" kadınların daha güzel veya zarif giyinmelerinden öte bir anlam taşımaktadır. Nitekim dönemin kadın dergilerinde konunun bu denli sıklıkla ele alınması da bu durumu teyit etmektedir.

1900'lü yıllarda modanın Avrupa'daki merkezi Paris ve Viyana'dır. Osmanlı bürokrasisinde Fransa'nın da kendine has bir konumu olduğundan modayla ilgili verilen haber ve örneklerde Paris'in ayrıca bir ağırlığı bulunmaktadır. Nitekim dönemin kısa süreli kadın dergilerinden biri olan Hanım'da yer alan şu ifadeler, kadın dergilerinin modayı Avrupa'dan Osmanlı'ya taşıdığını göstermesi açısından önemlidir:

"Bu sene pek büyük bir rağbete mazhar olan koton işlemeli rublar pek ziyade moda olduğu gibi çarpık kirmalı elbiseler Paris'te bilhassa Viyana'da görülmektedir. Kadın modalarının iki büyük hareket merkezi olan Paris ve Viyana gazetelerinden iktibas ettiğimiz bu üç modelden en baştaki yeldirmenin istihale geçirip kap haline gelmiş beyazlı siyahl güzel bir şeklidir...." (Hanım, 1 Eylül 1921:16).

Yazıda da belirtildiği üzere dönemin iki önemli moda merkezi olan Paris ve Viyana gazetelerindeki elbise modelleri okuyucuya tanıtılmaktadır.

Resim 3: Hanım Dergisinde "Moda” Başlığıyla Yayınlanan Bir Resim

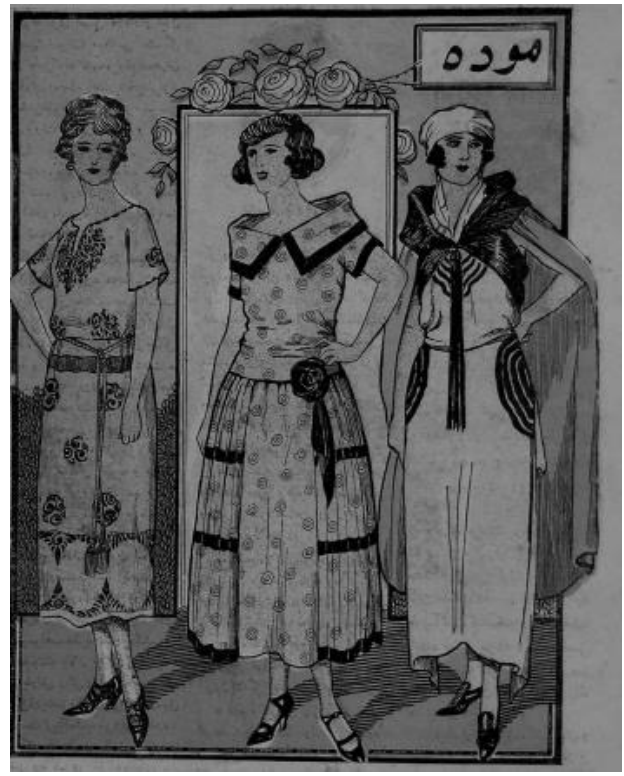

İlk sayfasında gazete satışından elde edilecek gelirin yüzde 5 'inin genç kızların gelinlik harcamalarına tahsis edileceğini ifade eden ve daha 
ziyade moda ağırlıklı bir yayın politikasına sahip olan Hanımlara Mahsus Gazete, kadınların kendi elbiselerini dikebilmeleri için hanımlara elbise kalıbı vereceğini ifade etmektedir. Gazetede örnek olarak verilen elbise illüstrasyon modelleri yine modern Batılı kadın çizimleri şeklindedir (Hanımlara Mahsus Gazete, 31 Ağustos 1311:4).

Resim 4: Hanımlara Mahsus Gazete'nin İlavesinde Yer Alan Bir Elbise Patronu

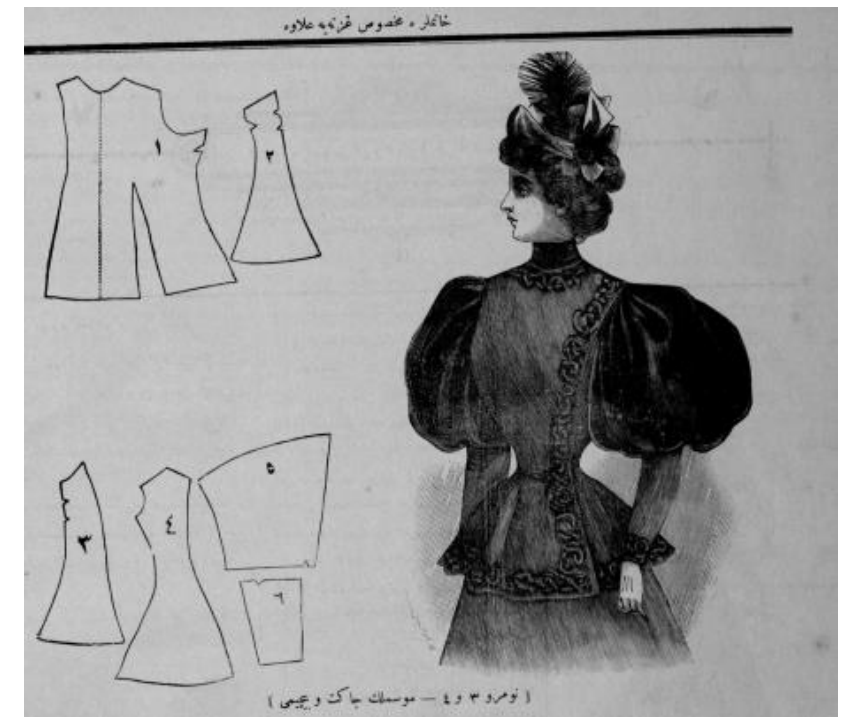

Kadın dergilerinin Batı kültürünü Osmanlı toplumuna taşımalarına verilebilecek en çarpıcı örneklerden biri de bu dergilerde kadının sadece dış giysilerinin değil aynı zamanda iç çamaşırlarının da konu edinilmesidir. $\mathrm{O}$ güne kadar toplumun yabancısı olan iç giyim modelleri, kadın cinselliği ön plana çıkartılarak ele alınmıştır. Örneğin; Mehâsin dergisinde yayınlanan "İç Çamaşırları" başlıklı yazıda kadının dış görünüşüne gösterdiği özeni iç çamaşırlarına da göstermesi gerektiği şu cümlelerle ifade edilmiştir:

"SSüphe yoktur ki hiçbir şey bir kadının ruh-i nisviyyetini iç çamaşırları kadar mükemmel olarak gösteremez. Evet, hakiki bir kadın için en mühim ve en birinci meşgale-i tezyîn yalnız gayet nefis bir surette tertib-i zevâhirden ibaret olmayıp diş elbiselerinden ziyade bir dikkat ve itinay-ı mahz ile iç çamaşırlarını tercih ve intihâbtır" (Mehâsin, Temmuz 1325:547).

İç çamaşırlarının doğru seçilmesinin kadının beğenilme arzusunu tatmin edeceğinin ifade edildiği yazının devamında aşağıdaki ifadelere yer 
verilerek söz konusu kıyafetlerin kadın üzerinde sadece kadının dış güzelliği değil, iç güzelliğini de göstereceği ifade edilmiştir:

"Her birisi avuçta büzülerek top haline getirilse bir pudra kutusuna sı̆̆acak kadar bir küme ancak teşkil eden bu çamaşırların şekil ve resimlerinin ehemmiyeti de gayr-i münkirdir. Çünkü bu resim ve şekildir ki kumaşın rikkat ve nezaketinden ziyade hâmilinin ruhundaki rikkat ve mümtâziyeti, zevkindeki rif'at ve istisnayı gösterecektir" (Mehâsin, Temmuz 1325: 547).

Dergilerde kadın giyimiyle ilgili olarak Batı kültürünün bir diğer yansıması da "tuvaletler"dir. Daha ziyade Avrupa kadınlarına özgü bir çeşit elbise olarak bilinen tuvaletler, dönemin kadın dergilerinde çokça yer almaktadir.

Giyim konusunda Batı tesiri sadece kadın giysilerinde değil aynı zamanda çocuk giysilerinde de dikkati çekmektedir. Dönemin kadın dergilerinde çocuklar için örnek olarak sunulan giysiler "son moda çocuk elbiseleri" başlıklı yazılar altında Avrupalı akranlarının elbise modellerine uygun bir şekilde, erkeklerde bermuda pantolon ve şapka, kızlardaysa kısa elbise ve şapkalarla resmedilmiştir (Kadın, 5 Temmuz 1328:25).

Kadının dış görünüşünün sıklıkla ele alındığı bir başka konu da kadınların saçlarıyla ilgili meselelerdir. Bir taraftan saç bakımı, saçların niçin döküldügü, saçın doğal renginin muhafaza edilmesi, saç ilaçlarının ne derece etkili olduğu gibi konulara dair yazı dizileri kaleme alınmış diğer taraftan da saç modelleri illüstrasyon çizimlere konu edinilmiştir. Nitekim 1919 tarihli Inci dergisine gönderilen bir okur mektubunda "kadınlı̆̆ın en klymetdâr hazine-i mehâsini olan saçlardan bahsedilmediğinden şikâyet edilmekte ve bize bu hususta pek hakl olarak serzenişde bulunulmaktadır" (İnci, 1 Nisan 1919:11) ifadelerine yer verilerek, derginin saç konusunda da okuyucuyu bilgilendirmesi istenmektedir. Dergi, okuyucu mektubunda dile getirilen bu hususa kayıtsız kalmayarak “Biz Inci'nin hizmetleri arasına bunu da sıkıştırmaya karar verdik. Ve bu nüshadan itibaren Avrupa'nın en şöhret-i şiâr müesseselerinin modellerini tedarikle kârilerimize arz eylemeye başladık. Bu hafta takdim eylediğimiz şu dört resim Viyana'da (Hu Friseure Pecil) müessesinin nazar-ı karib modelleri arasından intihâb edilmiştir" (İnci, 1 Nisan 1919:11) ifadeleriyle bu sayıdan itibaren okuyucuları için çeşitli saç modellerini takdim edeceğini duyurmuştur. 
Resim 5: Inci' de “Saç Modelleri” Başlı̆̆ıyla Verilen Fotoğraf

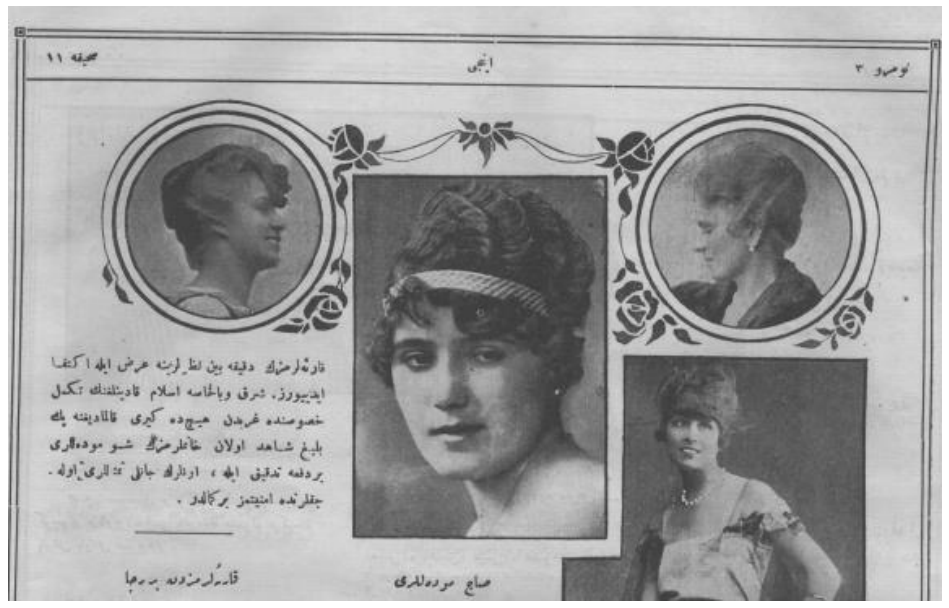

Dergide sadece saç modellerine yer verilmemiş aşağıda yer alan ifadelerle aynı zamanda okuyucudan saç bakımı ile ilgili tecrübelerini dergi aracıllğıyla paylaşması da istenmiştir:

"Saçların tarz-ı terbiye ve tertibi hakkinda Avrupa matbuatındaki satırları buraya aynen nakletmekle beraber her yerin ve her kadının zevki ayrıdır. Ve bunlar birbirinden tefrik eylemek lâzımdır. Biz bu nokta-ı nazarı takip ederek kârilerimizin de esaslı tecrübelerinden müstefid olmayı hatırladık. Bunun için de kendilerinden kadınlık âlemine bir hizmet dileyeceğiz. Saç terbiyesi ve tertibi, tuvaleti hakkında hanımlarımızın tecârüb ve mutâalâtı ne gibi şeyler olduğunu anlamak ve bunları neşr eylemek arzusundayız. Bize bu klymettar malumatı verecek lütfunda bulunacak hanımefendilere büyük minnetler perverde eyleyeceğiz" (İnci, 1 Nisan 1919:11).

Dergide dört saç modeline yer verileceği ifade edilmiş ve ilk olarak "Alabros" tarzı saç stili örnek olarak verilmiştir. Uzun saçlı kadınların saçlarını kesmeden arkadaki saçı tepeye doğru toplayarak, öndeki saçın, toplanan arkadaki saçların üzerine atılması şeklinde olan model, hem resimle hem de anlatımla okuyucuya sunulmuştur. Aynı şekilde 1920'li yıllarda bütün dünyada moda haline gelen ve saçın kısa kesilmesiyle erkeksi bir görünüm arz eden "Bob" tarzı saç modeli de dergide verilen bir diğer örnektir (Çetin ve Tüzer, 2017:218).

Dergide saçın tamamlayıcı bir unsuru olarak saç üzerinde kullanılan taraklara (tokalara) da yer verilmiştir:

"Yeni Saçlar ve Son Moda Taraklar" modanın yeni bir fantezisi, yeni kendisinin fantezisiyle anılan Bage Taraklar tekrar getiriyoruz. Siyah 
yahut kumral saç dalgalarının aynı renkte taraklarla imtizaç etmelerinden daha ahenktar bir şeyler olamaz. Her kuaföre göre imal edilmiş taraklar var. Başka hiçbir şey bütün zevk sahibi hanımların kullandiklart bu taraklar kadar tuvaletin mecmuunun zerâfetini, ihtişamını ikmâl edemez" (Kadın, 5 Temmuz 1328:8) ifadeleriyle saç üzerinde kullanılan tarak ve tuvaletin birbirini tamamlayan aksesuarlar olduğu belirtilmektedir.

\subsection{Kültür Taşınmasını Reklamlar Üzerinden Okumak}

Dönemin Osmanlı ekonomisi ithal ikameye dayalı bir görünüm arz ettiğinden gazete ve dergilerde yer alan reklam ve ilanların büyük çoğunluğunun Avrupa menşeili ürünlerden oluşması son derece doğaldır. Ancak bizim burada ele alacağımız reklam ve ilanlar daha ziyade o güne kadarki Osmanlı toplumunun tüketim kültüründe çok fazla yer edinmeyen ve Batı kültürünün Osmanlı toplumuna nüfuzunu gösteren reklam ve ilanlardir.

Bu reklamların çarpıcı bir örneğini “Oryantal Hapları Tesiriyle Güzel Bir Gögüs ve Bir Fidan Boy" başl1klı reklamda görmek mümkündür. Dekolte bir kadın resminin illüstrasyon çizimle tasvir edildiği reklam, bir kısmına aşağıda yer verdiğimiz uzun bir reklam metnine sahiptir:

"Hanımefendi, mütenasip bir göğ̈̈s ve besili bir gerdana mâlik olmak ister misiniz? Oryantal haplarından alını. Bunlar sayesinde Banyu Ferguson gibi harici vesâitle kesbî kâbil olmayan neticeler elde edeceksiniz. Zira gögüüün neşv-u nemâsı dâhili vesâite mutevaffiktır. Bu da ancak dâhili muâlecelerle olur. Oryantal haplart meme cildinin kanına takvd verir. Ve böylece memelerin neşv-u nemasına medâr olur. Bu haplar arsenik gibi muzır mevâdı hâvî olmayıp mukavva nebâtât hulâsasından mürettep olup sıhhate nâfi' olduğu gibi fazla şişmanlık da vermez" (Kadınlar Dünyası, 18 Kanunisani 1339:30). 
Resim 6: Kadınlar Dünyası'nda Yayınlanan “Oryantal Hapları” Reklam Resmi

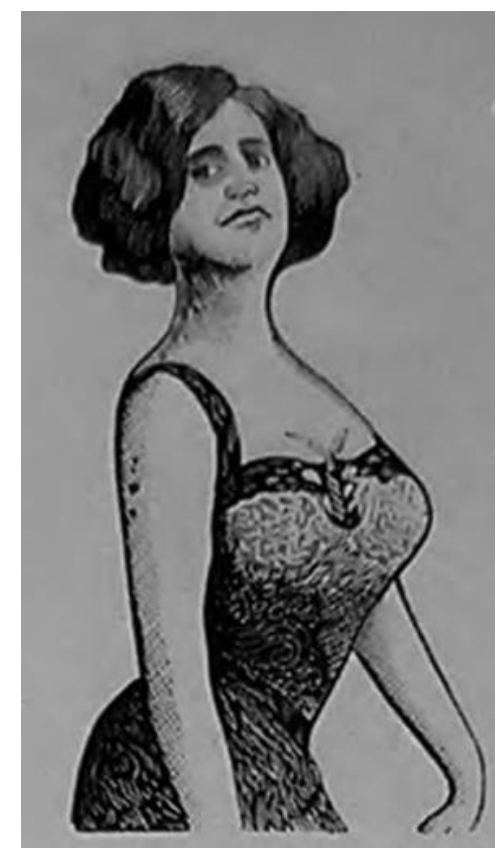

Postiş (peruk) reklamları incelenen kadın dergilerinde sıklıkla gördüğümüz reklamlardan biridir (Kadınlar Dünyası, 16 Teşrinisani 1329:18). Kadının giyimiyle ilgili bölümde de ele aldığımız üzere ilk kadın dergilerinde tartışma konusu tesettür üzerinden başlamış, zaman içinde kadının örtüsünün çıkmasına doğru evirilmiştir. Malum olduğu üzere peruk, saçın üzerine takılan bir aksesuardır. Dergi ve gazetelerde peruk reklamlarının sayılarının artması, toplumun "tesettür" konusunda bir değişim içine girdiğini göstermektedir.

Arkeolojik kazılarda ortaya çıkarılan takı ve süs eşyaları, kadınların güzel görünme isteklerinin tarihçesi hakkında bir bilgi vermektedir. "Korse"nin de 1850'li yıllardan çok önceki dönemlerde kadınların vücutlarını biçimlendirmek için kullanıldığı ancak kadın vücuduna özellikle doğum yapmamış kadınların ileride çocuk doğurmalarına zarar verdiği, bu nedenle çeşitli zamanlarda yasaklanma girişiminde bulunulduğu da bilinmektedir (Mürüvvet, 7 Mart 1303: 90). Konu, Osmanlı kadınının gündemine $1800^{\prime} l u ̈$ yıllardan itibaren girmiş, özellikle o yıllarda balina kemiklerinden yapılan korselerin vücudu biçimlendirmekle birlikte oldukça zararlı olduğu çeşitli yazılarda dile getirilmiştir. Özellikle dönemin muhafazakâr kadın dergilerinde konu sıklıkla ele alınmış, bunun 
bir Fransız modası olduğu ve kadın sağlığına zarar vereceği şu cümlelerle ifade edilmiştir:

"Kadınlara bile bile kendilerini hasta etmeğe ve envai göğ̈̈s illetlerine mübtelâ olup esir-i firâş eylemeğe sebep olan Fransız modalarından "korse" nin istimaline gelince onun tayîn-i mazarratı bile kâbil değildir" (Mürüvvet, 7 Mart 1303: 89).

Muhafazakâr kadın dergilerinde korsenin zararlarıyla ilgili yayınlar yapılmasına rağmen dönemin pek çok kadın dergilerinde korse reklamları sıkça yayınlanmıştır. Yukarıda da ifade ettiğimiz üzere dönemin moda merkezi Paris olduğundan kadın aksesuarı satan veya güzellik salonu işleten kişilerin Paris ile ilişkilendirilmesine de ayrı bir önem atfedilmiştir. "Paris Biçim Akademisinden Diplomall Madam Ferdinand'in Korseleri” (Kadınlar Dünyası, 9 Teşrinisani 1329: 19) başlıklı reklamda da olduğu üzere reklamı yapılan markanın, dönemin moda merkezi olarak telakki edilen Paris ile ilişkilendirilmesi dikkat çekmektedir.

Resim 7: Kadınlar Dünyası'nda Yayınlanan Bir Korse Reklam Resmi

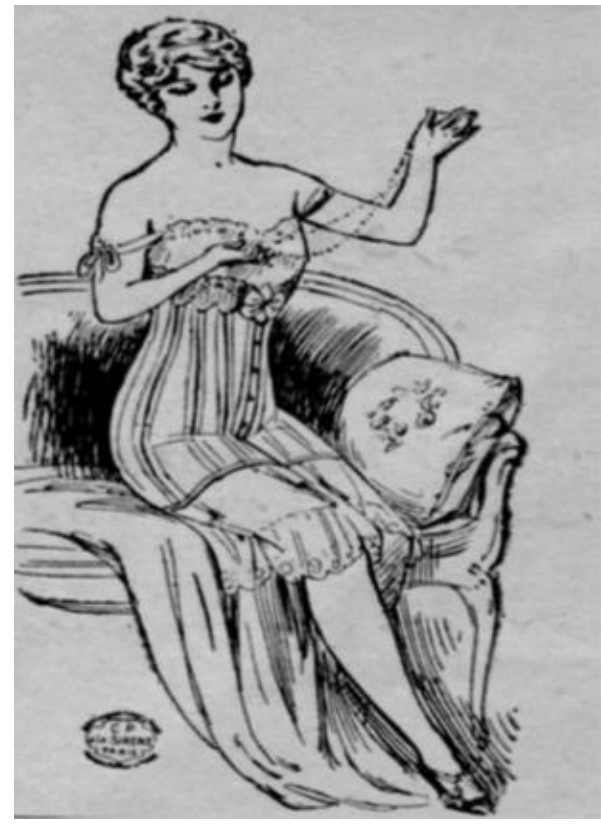

Bir kadın giysisi olarak tuvaletin dönemin kadınları arasında oldukça popüler olduğunu ifade etmiştik. Bu nedenle kadın dergi ve gazetelerinde reklamı en çok yapılan ürünlerden biri de tuvaletlerdir. Aynı şekilde dönemin kadınları arasında saç bakımı ve güzellik salonu "Hanımlara 
Mahsus Tuvalet Salonu; Mezkur salonun idaresi Paris saç salonu müessesesinden muallim diplomaslyla mezun Madam ve Mösyö Le Jun Furune'nin taht-ı nezâretindedir" (Kadınlar Dünyası, 8 Mart 1330:17) başlıklı reklamda da yine Batılı kadınlara özgü bir giysinin reklamı ve saç bakımı, Paris vurgusuyla yapılmaktadır.

Dergi ve gazetelerin içinde kimi zaman kadın giysilerinin nasıl dikileceğine dair patron olarak bilinen biçki kalıpları verilmiştir. Kimi zaman da "Son Moda Elbiseler-Patronları 5 Kuruştur" şeklinde satılık patron ilanlarına yer verilmiştir (Mehâsin, Eylül 1325:725).

Dönemin moda rüzgârının sadece açık kadınları değil tesettürlü kadınları da etkilediğinin en güzel örneklerinden biri de "Saç Tezyinâtı" başlıklı reklamdır (Kadınlar Dünyası, 9 Teşrinisani 1329:20). Reklam metninde, Güzellik salonunda Paris'in son moda postiş ve takma saçlarının geldiği, her saç rengine uygun boyaların bulunduğu belirtilmekte, "muhadderât-l İslamiye için" kadın görevlilerin çalıştı̆̆ istemeyenler için de evlere kadın görevlilerin gönderilebileceği ifade edilmektedir.

\section{Sonuç}

Osmanlı Devleti'nde Batılılaşma (modernleşme/alafrangalılık) 1839 tarihli Tanzimat Fermanı'ndan çok önceki tarihlere gitmekle birlikte, Tanzimat'ın ilanıyla devletin ve toplumun bütün kurumlarında köklü değişiklikler meydana gelmiştir.

$\mathrm{Bu}$ değişimin yansıdığ somut alanlardan biri de Osmanlı basınının doğuşudur. 1830'lu yıllarda ilk örnekleri ortaya çıkan gazeteler zamanla belirli bir toplumsal zemine kavuşmuş, bu durum kadın gazete ve dergilerinin doğuşuna da öncülük etmiştir.

En genel anlamıyla bir toplumun yaşam tarzı olarak ifade edilen ve maddi ve manevi unsurlardan karmaşık bir bütün oluşturan kültür öğesinin bir şekilden başka bir şekle geçmesi, yapı ve önemlerinin başkalaşması kültür değişmesi olarak ifade edilmektedir ve bu değişimler daha ziyade başka kültürlerle temas sonucunda ortaya çıkmaktadır. Kapalı bir toplum yapısına sahip olan Osmanlı toplumunda basın, Batı kültürünün Osmanlı toplumuna temasında önemli bir rol oynamıştır. Osmanlı modernleşmesinde çok önemli bir işlevi olan kadın dergilerinde hâkim olan düşünce, toplumun modernleşmesinin, kadının dönüşümüyle mümkün olacağı şeklindedir. Kadın dergilerinde ele alınan kadının eğitimi, kadın-erkek eşitliği, kadının toplumsal statüsü, moda, kadının giyim kuşamı, saç ve güzellik gibi konularla Osmanlı kadın kimliği Batılılaşma/modernleşme yolunda önemli mesafeler kat etmiştir. 
Tarihsel tecrübe, modernleşmenin daha ziyade diş görünüm üzerinden gerçekleştiğini göstermektedir. Benzer bir durum Osmanlı modernleşmesi için de söz konusudur. Giyim kuşam, saç ve güzellik gibi görünür öğelere sayfalarında bolca yer veren Osmanlı kadın dergileri Batı kültürünün Osmanlı toplumuna taşınmasında önemli bir unsur olmuştur.

\section{Kaynaklar}

Berkes, N. (2012). Türkiye’de Çă̆daşlaşma. İstanbul: Yap1 Kredi Yayınlar1.

Budak, A. (2014). Osmanl Modernleşmesi Gazetecilik ve Edebiyat. İstanbul: Bilgi Kültür Sanat Yayınları.

Çaha, Ö. (1996). Sivil Kadın: Türkiye'de Sivil Toplum ve Kadın. Ankara: Vadi Yayınları.

Çakır, S. (1996). Osmanlı Kadın Hareketi (2. Baskı). İstanbul: Metis Yayınlar1.

Çetin, E. ve Tüter, C. (2017). İnci Dergisi Üzerine Bir İnceleme. Milli Eğitim Dergisi, 216, s.203-225.

Gökalp, E. (2013). Sosyolojiye Giriş. Eskişehir: Anadolu Üniversitesi, Açıköğretim Fakültesi Yayını.

Kılıç. N. (2019). Osmanlı Basınında Muhafazakâr Bir Kadın Dergisi Mürüvvet. İstanbul: Kriter Yayınlar1.

Kurnaz, Ş. (1990). Cumhuriyet Öncesinde Türk Kadını. Ankara: Aile Araştırma Kurumu Başkanlığı Yayınları.

Lewis, B. (1984). Modern Türkiye’nin Doğuşu. (Çev. Metin Kıratl1). Ankara: Türk Tarih Kurumu Yayınları.

Nalcığlu, B.U. (2005). Tanzimat Dönemi Türk Gazeteciliği ve Türk Basınının İlkleri. Manas Üniversitesi Sosyal Bilimler Dergisi, 7 (14), s.253-267.

Ortaylı, İ. (2009). Osmanlı Toplumunda Aile. İstanbul: Timaş Yayınları.

Ortaylı, İ. (2018). Osmanlı Düşünce Dünyası ve Tarih Yazımı. İstanbul: Türkiye İş Bankası Kültür Yayınları.

Özen, H. (1994). Tarihsel Süreç İçinde Türk Kadın Gazete ve Dergileri: (1868-1990). İstanbul: Graphis Matbaa. 
Sürücü, G. (2008). Osmanlı Kadın Dergilerinde Kadının Dünyası (19081914). Yayınlanmamış Yüksek Lisans Tezi, Eskişehir: Anadolu Üniversitesi SBE.

Tekeli, Ş. (1985). Kadın Maddesi. Cumhuriyet Dönemi Türkiye Ansiklopedisi. cilt. 5, İstanbul: İletişim Yayınları.

Yıldırım, B. ve Seyhan, S. (2015). 1914 Yılında Yayınlanan Kadın Gazetelerinden "Kadınlık”a Göre Kadın. Galatasaray Üniversitesi Illetişim Dergisi, 23, s.39-65.

\section{Süreli Yayınlar}

Hanım

Hanımlara Mahsus Gazete

İnci

Kadın

Kadınlar Dünyası

Mehâsin

Mürüvvet 